\title{
Aortic valve replacement
}

\author{
V IK I N G O L O V B J Ö R K \\ From the Department of Thoracic Surgery, University Hospital, Uppsala, Sweden
}

The removal of calcium from calcified aortic leaflets seldom results in perfect function of the valve. The calcium will again be deposited on the leaflets and cause decreased mobility and stenosis within two to three years. Artificial teflon cusps, described by Bahnson, Spencer, and Jeckel (1961) and by Muller, Warren, Dammann, Beckwith, and Wood (1960), have been thickened by protein and calcium deposits and tissue ingrowth, and although the aortic insufficiency was eliminated some gradient remained over the orifice. Of the 15 patients operated upon using teflon cusps, 10 survived the operation, but in only two cases did the teflon cusps function satisfactorily after more than three years. Approximately 44 million bendings every year caused fatigue of the teflon and consequent rupture in seven patients after one to two years. The rupture of the teflon cusps occurred more rapidly in the patient than in the accelerated pulse duplicator due to the protein and calcium deposit on the cusps. In the eighth patient a small rupture occurred two years after the implantation. In this patient it was shown that the cusps, although thickened, had good mobility and no insufficiency or gradient at the one-year follow-up. During the second year the cusps underwent a progressive stiffening due to calcification. At the same time they tended to become shorter, causing insufficiency. In the ninth patient the teflon cusp ruptured after 3 years 4 months. Six patients were reoperated and the ruptured teflon cusps were excised. The insertion of a ball valve prosthesis was successful in four patients. The life expectancy of teflon cusps is too short for clinical application. I am therefore at present using only a ball valve prothesis, first advocated by Harken, Soroff, Taylor, Lefemine, Gupta and Lunzer (1960), and then perfected by Starr et al. (1963). Only on two occasions when the calcific orifice was too narrow to permit the use of a Starr prosthesis have I used pericardium for a total prosthesis as an emergency procedure. In both patients the pericardial cusps tore at the base and caused insufficiency and death after some months. In these cases I believe that the technique advocated by Harken et al., including a widening of the aortic root with a patch and a ball valve, is preferable. A Starr valve 8AT has, however, lately been used in this situation. As the results more than two years after using an aortic ball valve prosthesis are favourable, the aim of this paper is to give an account of the technique used and the difficulties and complications encountered.

\section{MATERIAL}

The material is summarized in Table I. Seventy-four patients, 12 women and 62 men, were accepted for aortic valve replacement using a ball valve prosthesis. The youngest patient was 15 years old, the oldest 57 years. Seven patients were more than 54 years of age and, of those, five survived. Thirty-one had a pure aortic insufficiency and 10 had a dominant aortic insufficiency with some degree of stenosis. Twenty-five

T A B LE I

MATERIAL

\begin{tabular}{|c|c|}
\hline No. of Cases & Diagnosis \\
\hline $\begin{array}{r}31 \\
10 \\
20 \\
1 \\
4\end{array}$ & $\begin{array}{l}\text { Aortic incompetence } \\
\text { Aortic incompetence }+ \text { aortic stenosis } \\
\text { Aortic stenosis }+ \text { aortic incompetence } \\
\text { Aortic stenosis } \\
\text { Aortic stenosis }+ \text { aortic incompetence }+ \\
\text { mitral stenosis }\end{array}$ \\
\hline 8 & $\begin{array}{l}\text { Aortic incompetence }+ \text { mitral incompe- } \\
\text { tence }\end{array}$ \\
\hline
\end{tabular}

Total 74

patients had calcific aortic stenosis, and, of those, 23 had a significant insufficiency as well ; four had a tight mitral stenosis necessitating a transventricular dilatation at the same operation. In eight patients the aortic insufficiency was combined with a mitral insufficiency, which was simultaneously treated in six patients; four had a ball valve prosthesis and two an annuloplasty. None of these eight patients survived.

\section{METHOD}

A midline sternotomy was performed, and both cavae were cannulated through the right auricular appendage. The external iliac artery was used for cannulation. The left ventricle was drained through its apex. The heart-lung machine with the spinning disc oxy- 


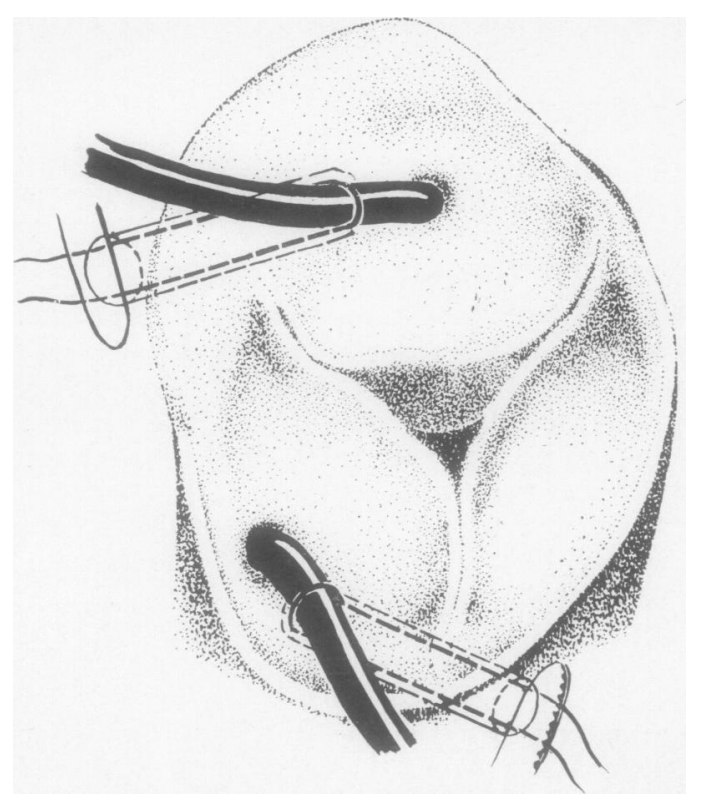

genator was started with a small flow (usually 2 litres/min.) until a clamp had occluded the ascending aorta. In the presence of aortic and mitral insufficiency a high flow may initially damage the lungs. Therefore the left ventricular drainage tube was continuously aspirated from the beginning, the aorta was cross-clamped as soon as possible, and after that the perfusion rate was increased to $2 \cdot 2$ litres $/ \mathrm{m}^{2}$ body surface area. A transverse aortic incision was preferred. The valves were inspected and then resected. From a side branch of the arterial line blood was supplied through a catheter using a metal tip with self-inflating rubber cuff introduced into each coronary artery and kept in place during the whole procedure by the suture tightened through a rubber tube on the outside of the aorta (Figs. 1 and 2). When the coronary artery orifice was too small to permit the introduction of the catheter, a metal cannula on a handle was held in place. Local hypothermia with crushed ice was never used when satisfactory coronary perfusion could be obtained.

Both right and left coronary artery perfusion can usually be continued throughout the whole procedure. Twice the metal cannula perforated the right sinus of Valsalva ; this was repaired from the inside of the aorta with recovery in both patients. Coronary artery perfusion was started once the aorta had been opened in all patients except those with heavy calcification. In the latter it is preferable to postpone coronary artery perfusion until the calcium has been excised. Care must be taken not to damage the anterior mitral leaflet when the non-coronary cusp close to the left cusp is excised. In one patient a large calcific mass extended from the aortic cusp through the mitral cusp. After removal of the heavily calcified non-

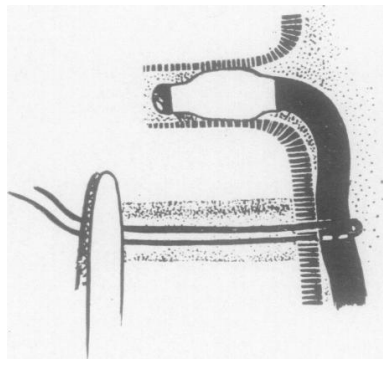

FIG. 1. The coronary artery perfusion cannula kept iT position by a 4-0 suture drawn taut through a rubber tube from the outside of the aorta.

coronary cusp a large hole was produced in the్ anterior initral leaflet. If possible, a rim of tissue although calcified, must be left in situ for suturing the prosthesis in place. Care must be taken to remove all loose fragments of calcium piece by piece in the

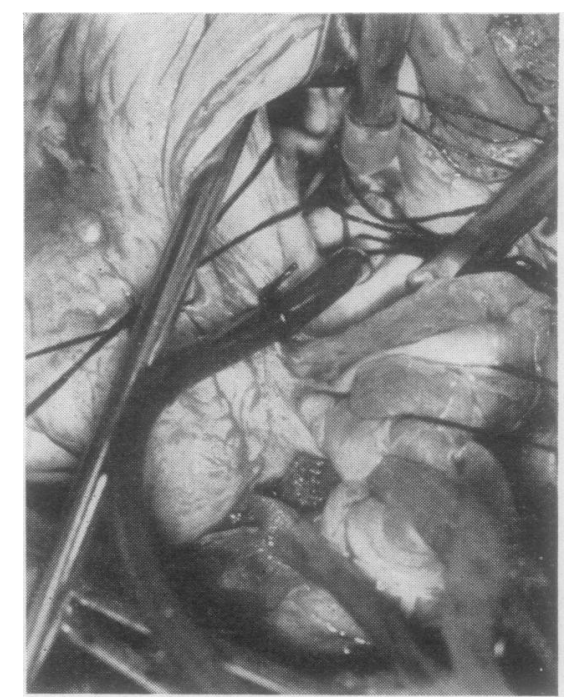

FIG. 2. The plastic cannula has been introduced into th@ left coronary artery and kept in place by the suture frorf the outside of the aorta. The metal cannula for right coronary artery perfusion is also held in place while the sutures for the prosthesis are being introduced. 


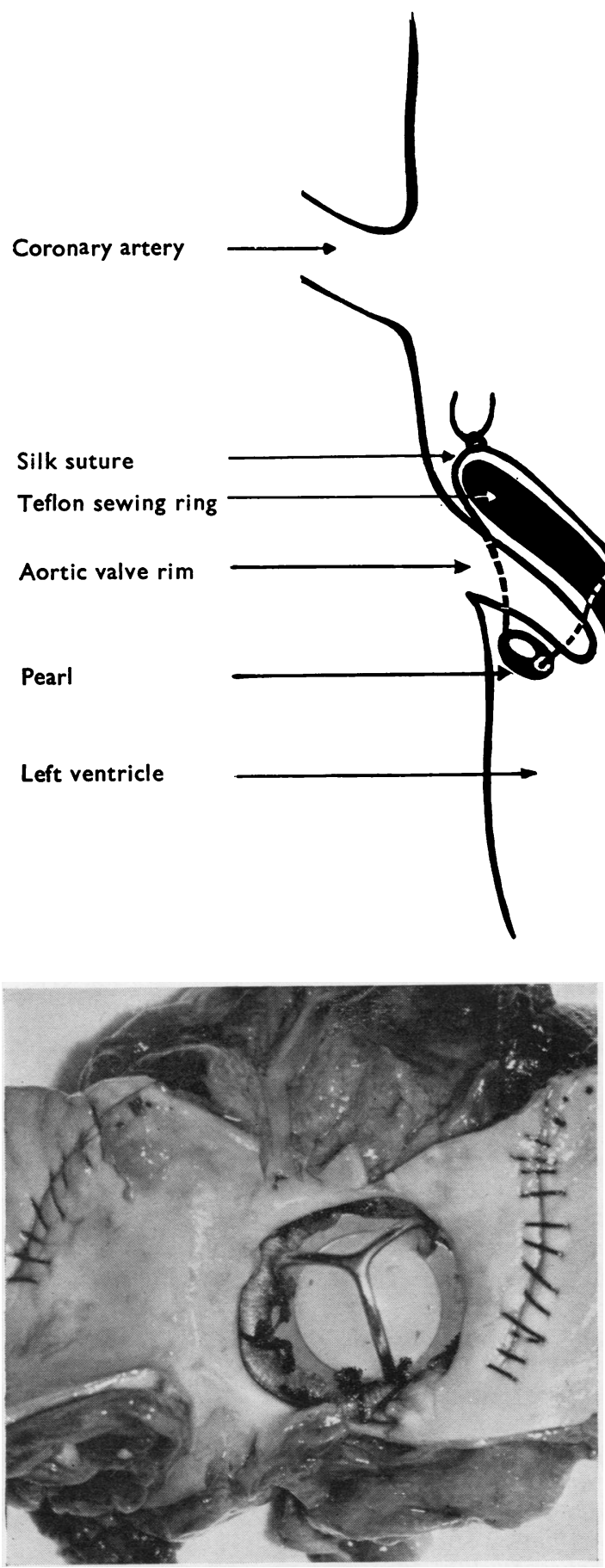

FIG. 4a. A necropsy specimen showing the prosthesis in the proper position $1 \mathrm{~cm}$. below the coronary arteries. The opened left artery is visible in the left lower corner, the right in the left upper corner of the prosthesis.
FIG. 3. Diagram showing how the mattress suture is buffered on the ventricular side. Only one end of the suture is passed through the sewing ring, and when the sutures are tied this comes away from the cage and the ball.

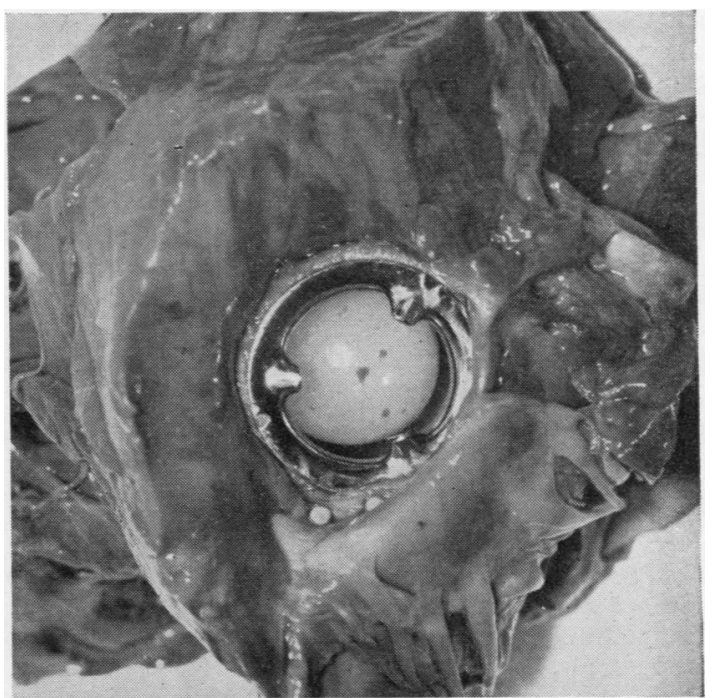

FIG. 4b. The same specimen as in Fig. 4a. When pr.sperly placed the prosthesis protrudes down into the left ventricle. Subvalvular calcifications, especially on the anterior mitral valve or on the interventricular septum, must therefore be removed and the prosthesis pushed down once before the sutures are fixed. Some teflon pearls buffering the sutures in the area corresponding to the anterior mitral leaflet are seen. 
raw area left for suture to prevent embolization. Subvalvular calcific masses must be excised in order to permit the introduction of the prosthesis far enough into the left ventricle to leave the coronary ostia unobstructed. The ostium is then measured with an obturator shaped in the same way as the prosthesis to ascertain the size that fits. The prosthesis chosen must also be tested in the ostium before it is sutured in place. It is important not to use too big a prosthesis because, if it is difficult to place the prosthesis, the sutures may cut through and a pressure necrosis will result.

Number $\mathbf{O}$ silk sutures on small double needles were introduced from the ventricular side. The thread was buffered by a teflon pearl in order to prevent the suture from cutting through (Fig. 3). The needles should not be allowed deep bites at the base of the anterior part of the non-coronary cusp and the right part of the right aortic cusp in order to avoid the bundle of His. All the sutures were placed first as mattress sutures around the ostium, one low down in each commissure and then usually three to five sutures in between; in all, 12 to 18 sutures were used. The commissure sutures were passed through the collar of the prosthesis as horizontal mattress sutures. Only one end of the other sutures was passed low down through the sewing ring so that when tied it was pressed away as much as possible from the ball cage to prevent narrowing of the passage of blood. The sutures low down in the commissures were tied last, as they usually narrow the orifice and may then prevent the prosthesis from settling in the proper position. It is advantageous to have the cannulae in the coronary ostia when the sutures are tied so that one is convinced that the prosthesis will be fixed low enough (Fig. 4). During closure of the aortotomy the cannulae in both coronary arteries can be left in place. A continuous over-and-over 3-0 silk suture was used first in the left and then in the right third of the incision, and isolated mattress sutures were placed around the cannula in the middle third of the aortic incision. When all the stitches had been placed, the cannulae in both coronary arteries were removed after cutting the sutures outside the aortic wall. The isolated sutures were tied and the aortic clamp was removed. The leakage around a ball valve prosthesis is negligible during the first few minutes and the perfusion can therefore continue for some minutes to provide optimal coronary perfusion. The occluding tapes around the vena cava were released and the left ventricular vent was removed, tilting up the apex of the ventricle to remove any residual air. To prevent the ball from becoming fixed, a nylon suture is passed through the valve orifice into the ventricle and is removed through the aortotomy incision. The danger of a fixed ball is not as great with a beating heart as during fibrillation. If the click of a functioning prosthesis is not confirmed by palpation, a probe is quickly inserted through the apex of the left ventricle to dislodge the ball from its closed position. The perfusion can then be reduced and the heart is usually ready to take over the circulation within five minutes after release of the aortic occlusion. The average perfusion time iof surviving patients was 91 minutes, with the shortest. duration 55 minutes and the longest perfusion 13 minutes. The average time of aortic occlusion was $7 \mathbb{B}$ minutes with a range of 51 to 93 minutes. The perie cardium and mediastinum were drained. Heparin.? $3 \mathrm{mg}$. per kg. body weight as a single dose, was used $\overrightarrow{0}$ and this was neutralized with an equal dose of pro tamine sulphate injected slowly into the right atriumw Primary tracheostomy with a volume regulated respi rator (Engström) was used in all patients with a ver度 big heart and in a bad condition for the first week Respirator treatment through the remaining intra tracheal anaesthesia tube was used for the first nightw in patients with a significantly enlarged heart. Ora? anticoagulant treatment was started on the fifth posto operative day and continued for life.

\section{RESULTS}

MORTALITY Of the 74 patients operated uponक 38 are living, seven have been observed for more than two years, and 20 patients for more thare one year. The last 15 consecutive patients have survived the operation. Thirty-six patients diech and the cause of death was sepsis (12), myocardiaf failure (15), technical failure (5), and complica tions (4).

Sepsis of 17 patients with blood stream infec tion, 12 died from this sepsis while three died after three, four, and seven days from circulatory. failure with a positive blood culture. Only twof patients, who had one positive culture of Staphylo coccus albus and received 30 million units of peni cillin a day for six weeks, recovered. The bloof stream infection was caused by Staph. aureus in 11 patients and by Staph. albus in six. Coli and enterococci were also cultured from two patients. Of the seven patients who died from sepsis within 55 to 134 days after the operation, all seven had suture insufficiency around the prosthesis with a․ false aneurysm in the sinus of Valsalva. The suture insufficiency was always found in the weak area around the commissure between the left and the? right aortic cusps. In one patient as much as two- $\omega$ thirds of the circumference of the prosthesis had become loose. The suture insufficiency could be demonstrated as an abnormal tilting of the prosthesis by each heart cycle by cineradiography at ${ }^{+}$ an early stage. Among eight patients with sepsis, $\frac{T}{0}$ who died three to 24 days after the operation, only two had a suture insufficiency and none had an $\frac{\rho}{\Phi}$ aneurysm.

Myocardial failure This was the cause of death in 15 patients. Eight of these also had a $\Omega$ significant mitral insufficiency which in six waso 
operated upon at the same time as the aortic insufficiency, in four with ball valve prostheses and in two with annuloplasty. The remaining deaths were three patients who required a further operation after rupture of the teflon cusp ; a 56year-old man who had a large heart of $840 \mathrm{ml}$./ $\mathrm{m}^{2}{ }^{2}$; two patients with a heart size of $1,000 \mathrm{ml}$./ $\mathrm{m}^{2}$; and a patient with a heavily calcified orifice where, after removal of the ostium, no rim of the right cusp remained. The fixation sutures then had to transgress the upper portion of the ventricular septum and caused severe arrhythmia with death on the seventh post-operative day. Necropsy showed that the sutures had passed through the right ventricle just below the pulmonary valves and through the right atrium. Serial sections demonstrated bleeding and suture close to, but not through, the bundle of His.

Technical failure This was the cause of death in five patients. The prosthesis chosen was too big in two. In one of them a subvalvular calcific mass made it impossible to put the prosthesis in the proper position. The left coronary orifice was obstructed. All sutures had to be cut, and a smaller prosthesis was introduced. As the aortic root was narrow, a patch had to be used for closure of the aortotomy. Leakage at one point in the suture line necessitated some extra sutures, one of which occluded most of the right coronary artery. The heart's failure to take over the circulation was ascribed to a three and a half hours' perfusion with 158 minutes' aortic occlusion. The heart was packed in ice but only 114 minutes of left coronary artery perfusion could be given. The situation was misjudged and a right coronary artery obstruction was suspected too late.

In the second patient a prosthesis that was too big caused erosion of the ventricular septum and a big interventricular communication through the septum. The sudden shunt caused pulmonary oedema and death 19 days after operation. In the third patient, who had extensive subvalvular calcifications, a large hole in the anterior mitral leaflet was produced when the masses of calcium in the aortic orifice were found to extend through the mitral leaflet and were removed. A direct repair using the teflon sewing ring of the prosthesis held for only a few minutes, and the patient succumbed in mitral insufficiency.

Ball obstruction was encountered in two patients. In one very narrow aortic orifice in a woman, where a no. 9 prosthesis had been placed with difficulty, the sewing ring obstructed the ball (Fig. $5 \mathrm{a}$ and $\mathrm{b}$ ). The other ball obstruction was due to thrombosis in a patient with ventricular ulcer (Fig. $6 \mathrm{a}$ and $\mathrm{b}$ ). The patient had a huge heart of $900 \mathrm{ml} . / \mathrm{m}^{2}{ }^{2}$ and a no. 12 Starr Edwards ball valve prosthesis. When his prothrombin time was lowered by dicoumarol to 18 he experienced severe bleeding from his ulcer. Vitamin $\mathrm{K}$ and a blood transfusion rapidly brought the prothrombin time back to normal and this resulted in thrombosis in the sewing ring of the prosthesis with intermittent obstruction of the ball, left ventricular failure, and death on the nineteenth post-operative day.
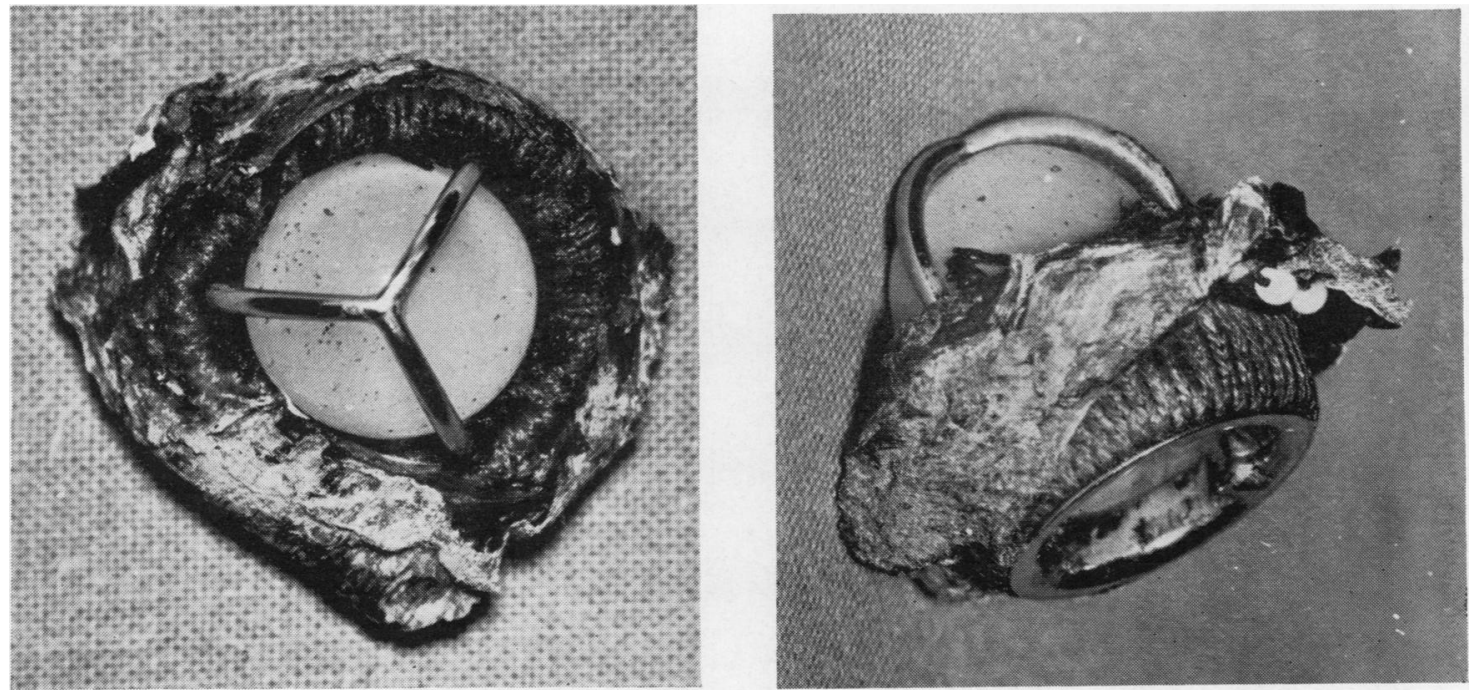

FIG. 5 Necropsy specimen showing how the sewing ring obstructs the ball. 


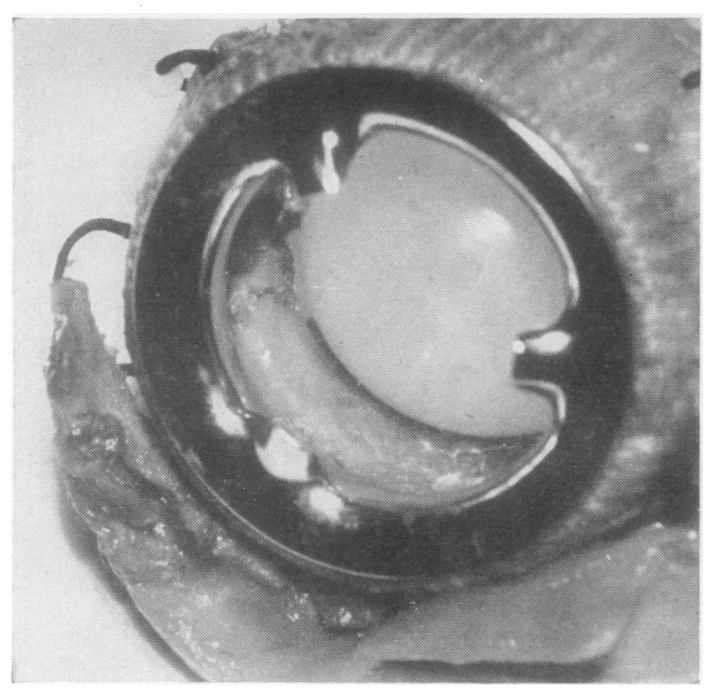

Complications Four patients died from uraemia resistant to repeated treatment with the artificial kidney.

SURVIVALS Of the 38 surviving patients, seven have been followed for more than two years and 20 for more than one year. There have been no late complications. All but one patient had competent valves at follow-up. Two recent patients have a diastolic murmur but a decreasing heart size. A short systolic murmur could be heard over the aortic area corresponding to a small systolic pressure gradient. The gradients measured at the end of operation are summarized in Table II. Usually a better result was obtained when too big a prosthesis was avoided. Although the flow was not measured in all patients during surgery, it was evident that in most cases, especially if a smaller prosthesis was chosen, the gradient was insignificant or less than $5 \mathrm{~mm}$. $\mathrm{Hg}$. One patient with a no. 13 prosthesis had a gradient of 24 at surgery and one year after the operation $20 \mathrm{~mm}$. $\mathrm{Hg}$ at a

T A B LE II

SYSTOLIC GRADIENT BETWEEN THE LEFT VENTRICLE AND THE BRACHIAL ARTERY AT THE END OF

\begin{tabular}{c|c|c|c|c}
\hline $\begin{array}{c}\text { Starr } \\
\begin{array}{c}\text { Prosthesis } \\
\text { No. }\end{array}\end{array}$ & $\begin{array}{c}\text { Hydraulic } \\
\text { Opening } \\
\text { (mm. diam.) }\end{array}$ & $\begin{array}{c}\text { No. of } \\
\text { Cases }\end{array}$ & $\begin{array}{c}\text { Average } \\
\text { Gradient } \\
\text { (mm. Hg.) }\end{array}$ & Range \\
\hline 8 & $13 \cdot 2$ & 2 & 10 & -5 to 26 \\
9 & $14 \cdot 3$ & 2 & 0 & 0 \\
10 & $15 \cdot 2$ & 5 & 4 & -2 to 26 \\
11 & $16 \cdot 2$ & 10 & -4 & -20 to 20 \\
12 & $17 \cdot 2$ & 15 & 4 & -39 to 40 \\
13 & $17 \cdot 8$ & 11 & 18 & -20 to 68 \\
14 & & 1 & 20 & \\
\hline
\end{tabular}

FIG. 6. Shows thrombosis inside the sewing ring obstruct ing the ball.

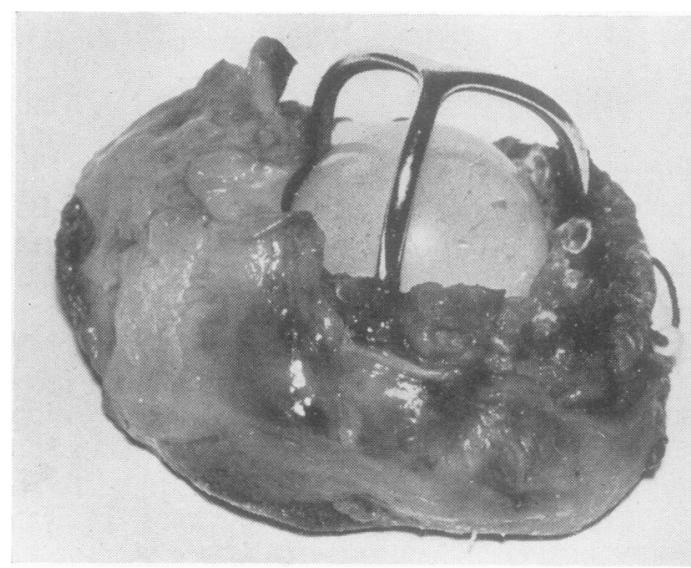

flow of $6 \cdot 8$ litres, and still $20 \mathrm{~mm}$. $\mathrm{Hg}$ at $9 \cdot 2$ litres, rising to $40 \mathrm{~mm}$. $\mathrm{Hg}$ at 13 litres per minute. A 24year-old woman with a huge heart of $800 \mathrm{ml} . / \mathrm{m}^{2}{ }^{2}$ had a free aortic insufficiency, due to septic perforations as well as prolapsing cusps, with an aneurysm of the sinus of Valsalva intact but bulging into the right atrium (Fig. 7 a-f).

After two years the heart had diminished in size to $440 \mathrm{ml} . / \mathrm{m}^{2}{ }^{2}$ with a competent prosthesis and obliteration of the aneurysm (Fig. $7 \mathrm{~g}, \mathrm{~h}$, and i). The gradient over a no. 12 Starr Edwards ball valve prosthesis was $13 \mathrm{~mm} . \mathrm{Hg}$ at the end of the operation, but $15 \mathrm{~mm}$. $\mathrm{Hg}$ after nine months at a flow of 8.8 litres per minute increasing to $35 \mathrm{~mm}$. $\mathrm{Hg}$ at a flow of 13 litres per minute. The gradient at follow-up was measured between the left ventricle and the aorta. In the last 30 consecutive cases where the importance of detail in suture technique was observed, especially to bring the sewing ring away from the cage and to choose a prosthesis that was not too big, the average gradient was $-3 \mathrm{~mm}$. $\mathrm{Hg}$ (range -20 to $10 \mathrm{~mm}$. $\mathrm{Hg}$ ) between the left ventricle and the brachial artery.

\section{DISCUSSION}

The technique of placing individual cusps of teflon or silastic or cusps mounted together on a frame gave good immediate results. The cusps were hinged high in the commissures and most were completely competent when followed up one year later.

The immediate mortality was five out of 15 patients using teflon cusps. After one year the 


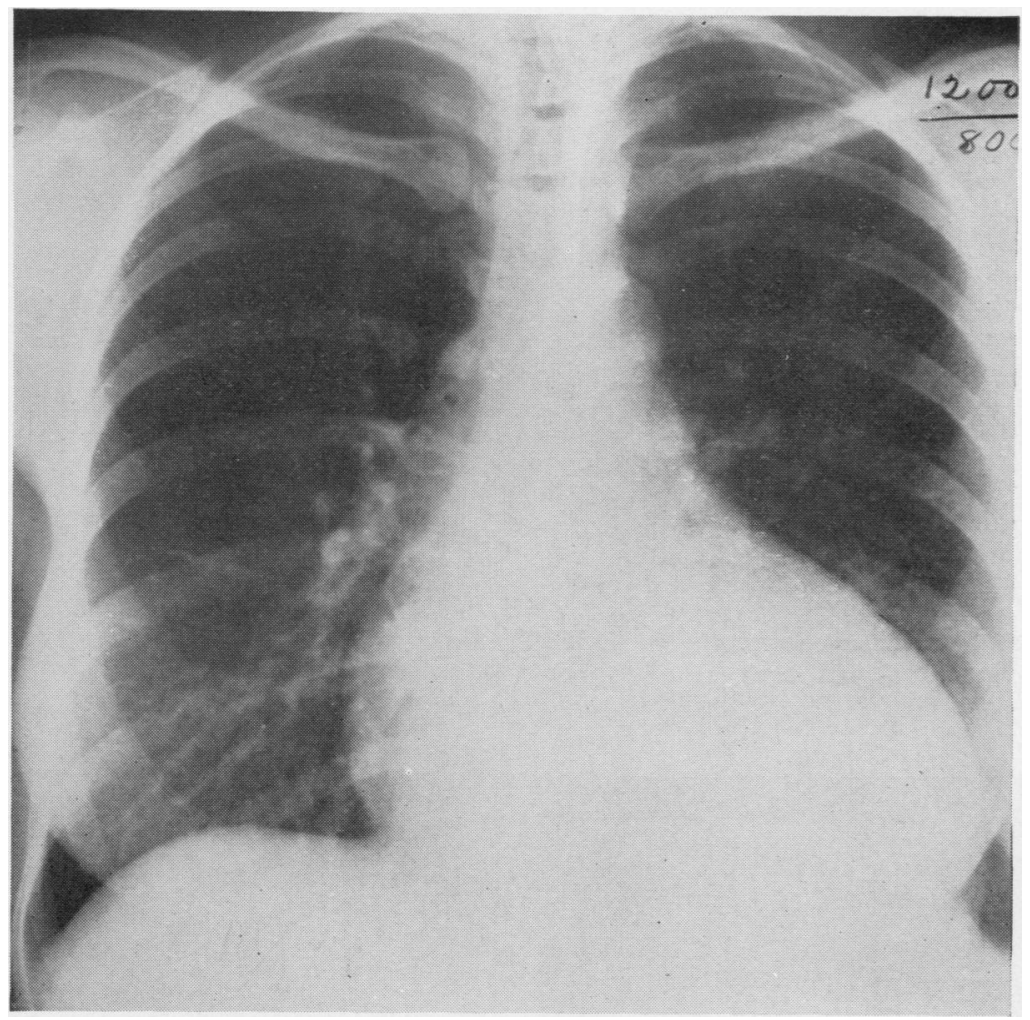

FIG. 7a. Chest radiograph of a 24-year-old woman with aortic insufficiency and a huge heart of $800 \mathrm{ml} . / \mathrm{m} .^{2}$.

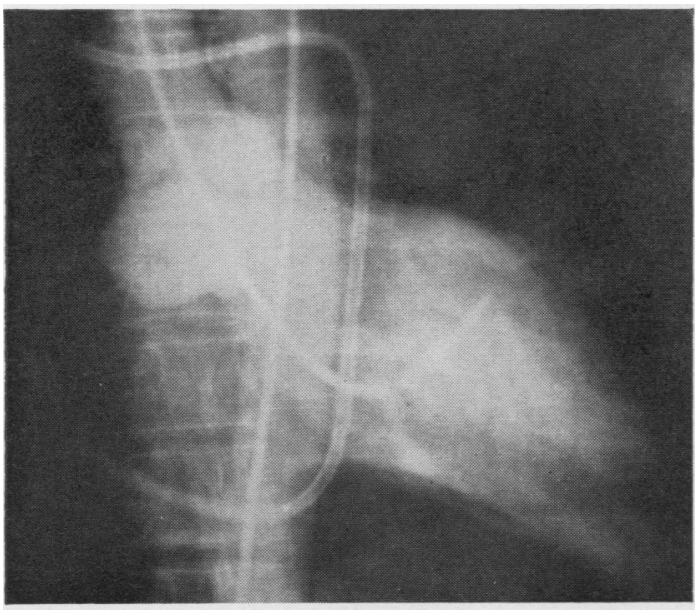

(b)

FIG. 7 (b and c) Thoracic aortography shows free aortic insufficiency and a $h$ uge ane urysm of the sinus of Valsalva.

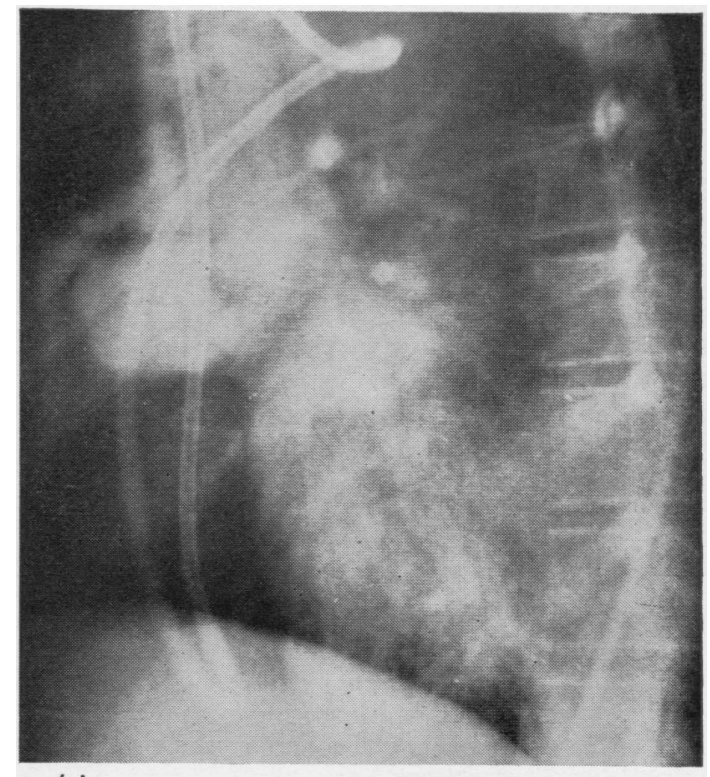

(c) 


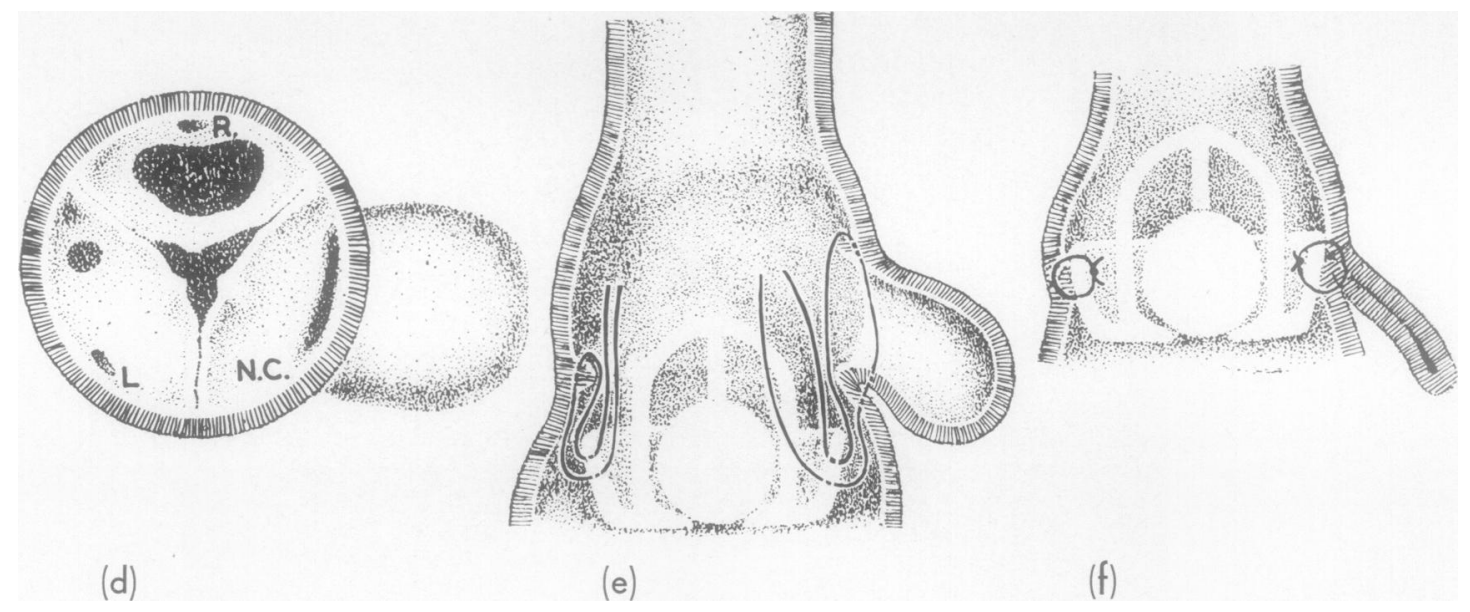

FIG. 7. (d) The findings at operation with a large perforation in the right aortic cusp $(R)$ and a small perforation in the left $(L)$ as well as a thumb-sized aneurysm of the non-coronary sinus of Valsalva. (e and f) The suture technique for obliteration of the sinus of Valsalva aneurysm with the aid of a prosthesis.

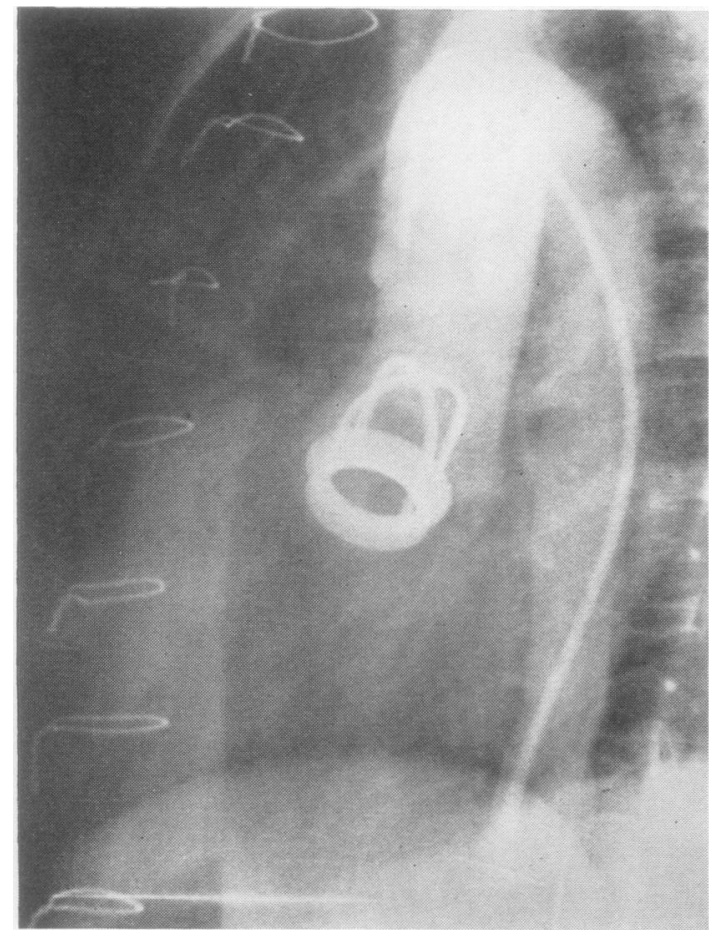

(g)

FIG. 7. (g and h) Thoracic aortography nine months after implantation of a ball valve prosthesis shows a competent valve and obliteration of the aneurysm of the non-coronary sinus of Valsalva utilizing the sewing ring of the Starr Edwards no. 12 prosthesis.

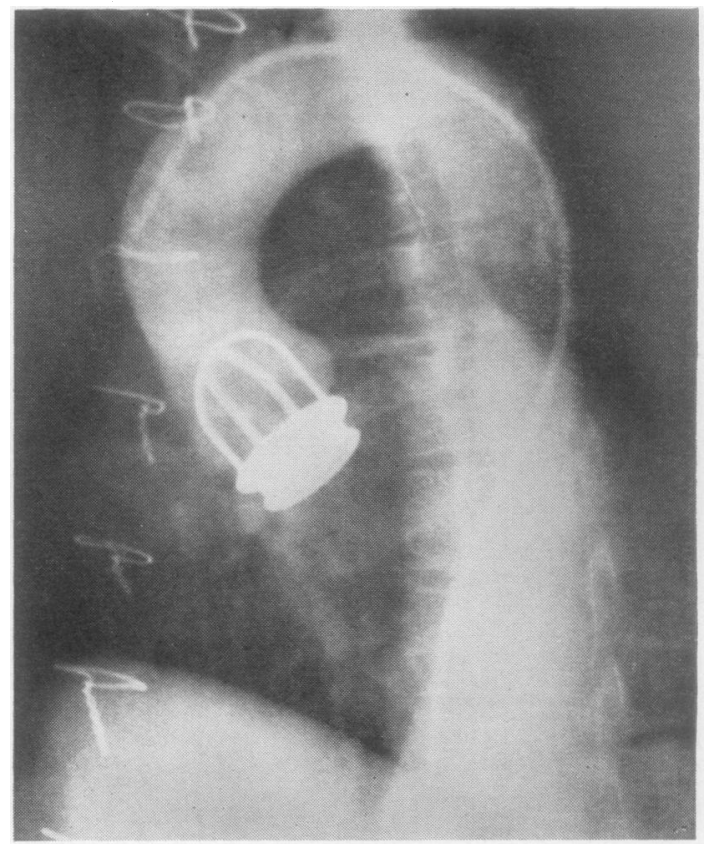

(h) 


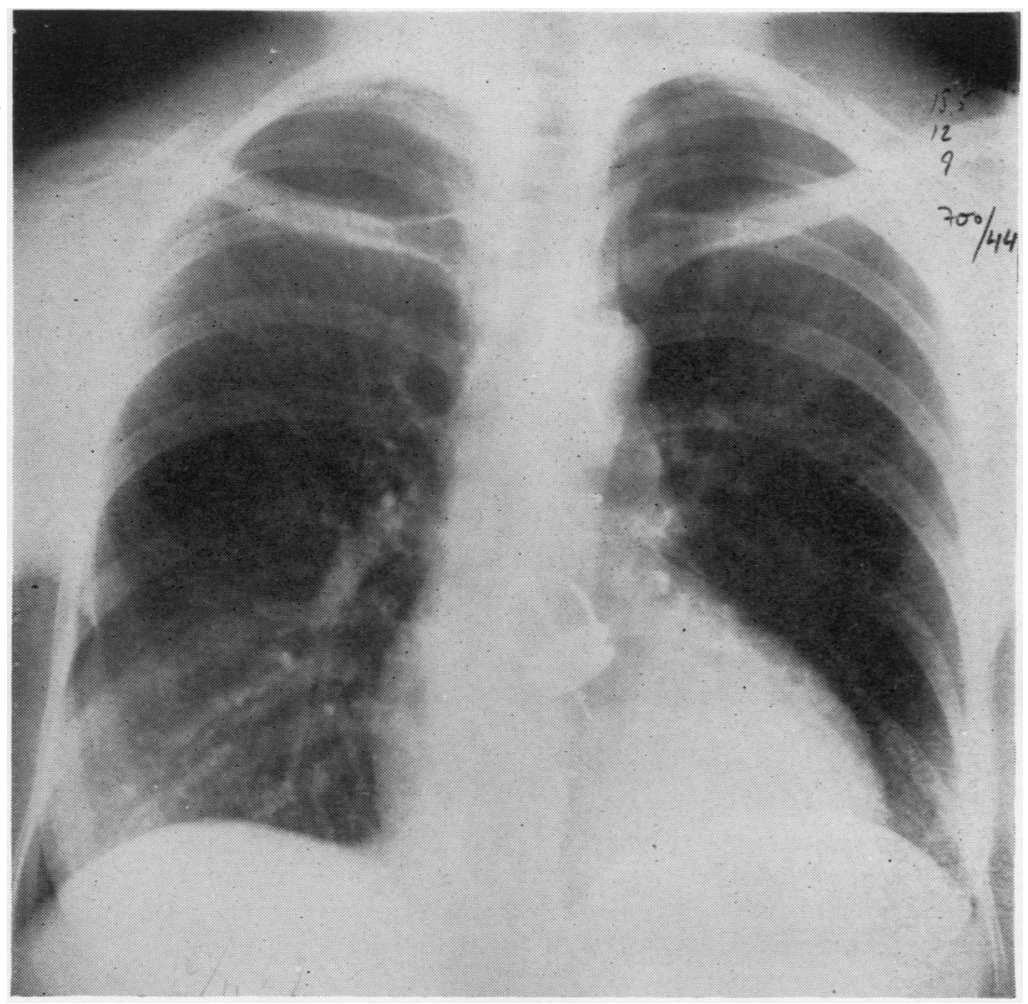

FIG. $7 \mathrm{i}$. Chest radiograph shows reduction in heart size from 800 to $440 \mathrm{ml} . / \mathrm{m}^{2}$ body surface two years after operation.

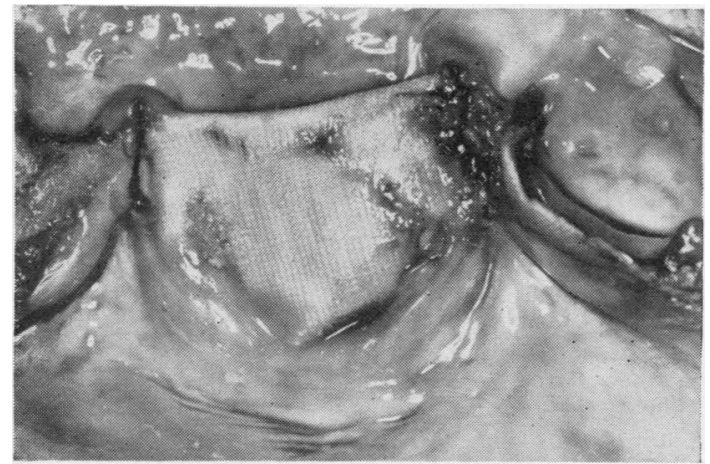

FIG. 8a. Three individual teflon cusps after two ycars well healed and in place but stiff and shrunken and without mobility.

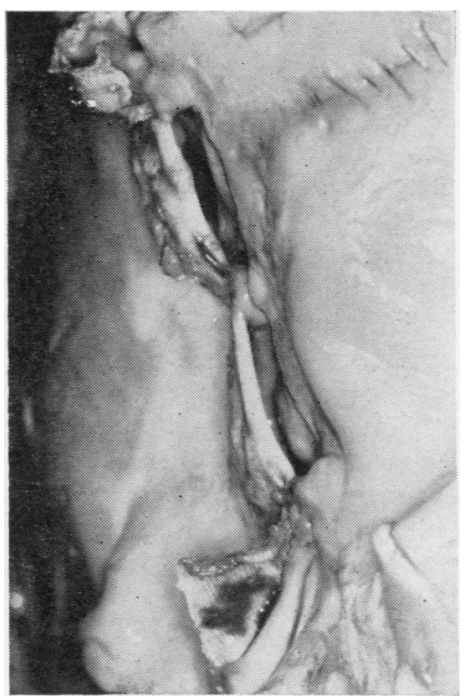

FIG. 8b. The same teflon cusps as in Fig. 8 a showing shrinkage and thickened edges. 

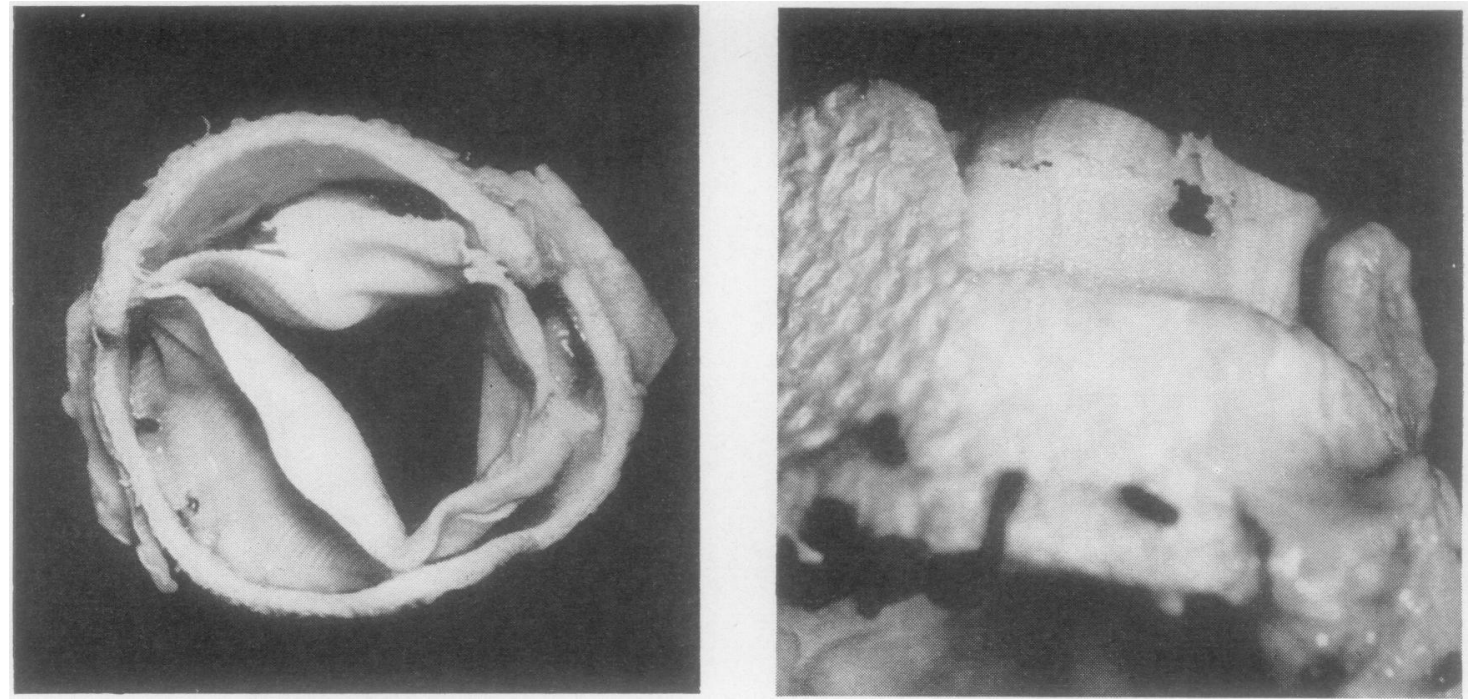

FIG. 9. A teflon prosthesis removed after one and a half years from a patient in whom the individual cusps are mounted on a teflon frame. The cusps have folded in the wrong direction, and this caused a hole with insufficiency.

cusps had ruptured in two patients. After two years five more patients had ruptures and the cusps were stiffened and shrunken to such a degree that they caused both stenosis and insufficiency (Fig. 8 a and b). Only one patient still has a functioning teflon cusp after three and a half years. One difficulty with the individual cusps, even if mounted on a stiff teflon frame, was a tendency to fold in the wrong direction with breakage of the teflon and insufficiency (Fig. 9). Of the seven patients who had lived for more than two years with a ball valve prosthesis, none had had late complications. Harken was the first to advocate a ball valve prosthesis for subcoronary implantation. Starr and Edwards have refined the prosthesis so that it can be introduced in an average of 70 minutes (in the last 20 cases). The real difficulty is the pathology, especially in the calcific cases. The mortality can be reduced with experience. The high incidence of blood-stream infection must be improved. The late occurrence of endocarditis has not yet been observed. The results seen are sufficiently encouraging to justify the acceptance of a ball valve prosthesis, of the Starr Edwards type, as the method of choice for the present.

Anticoagulant treatment for life is a necessity. One 54-year-old patient, who had a transventricular dilatation of mitral stenosis at the same time as an aortic prosthesis, had dicoumarol therapy discontinued for one month six months after the operation when an embolus to the left leg was experienced.

\section{SUMMARY}

An account is given of experience with total aortic valve replacements, 15 cases with teflon cusps and 74 cases with a ball valve prosthesis. The technical difficulties encountered in aortic valve replacement are analysed. The results obtained with the ball valve prosthesis are encouraging. Only very advanced cases should be accepted in this stage of development.

Hamlet's words: 'Diseases desperate grown by desperate appliance are relieved or not at all' is true for patients with aortic valvular disease.

\section{REFERENCES}

Bahnson, H. T., Spencer, F. C., and Jeckel, N. C. (1961). Experiences with replacement of individual cusps of the aortic valve. In Prosthetic Valves for Cardiac Surgery, ed. K. A. Merendino, p. 440. Thomas, Springfield, Ill.

Harken, D. E., Soroff, H. S., Taylor, W. J., Lefemine, A. A., Gupta, S. K., and Lunzer, S. (1960). Partial and complete prostheses in aortic insufficiency. $J$. thorac. cardiovasc. Surg., 40,744 .

Muller, W. H., Warren, W. D., Dammann, J. F., Beckwith, J. R. and Wood, E. J. (1960). Surgical relief of aortic insufficiency by direct operation on the aortic valve. Circulation, 21, 587

Starr, A., Edwards, M. L., McCord, C. W., and Griswold, H. E. (1963). Aortic replacement: Clinical experience with a semi-rigid ball-valve prosthesis. Circulation, 27, 779. 